\title{
Qualitative Research, Intent and Expression
}

\author{
WALTER S. GERSHON \\ Kent State University (USA)
}

This brief essay addresses the possibility of nested layers of intent and expression as an alternative to the construct of "validity" for qualitative researchers. As a construct for qualitative methodologists, validity has been a site of tension and struggle. Validity is often understood as the ability to accurately measure what one sets out to measure. This understanding is problematic on two counts. First, as Geertz (1973) notes, human interaction while patterned is not predictive, which makes measurement between any two instances of human interaction difficult at best. Second, the purpose of qualitative research is most often not to measure but come to some understanding what such interactions mean (Agar 1986; Erickson 1986).

Qualitative researchers in education have most often approached validity in one of two ways. On one hand are those who seek to reformulate this borrowed positivist construct as a criterion for qualitative studies (Lather 1986; Maxwell 1990). On the other are those who reject validity in favor of other constructs they believe to be more appropriate for interpretive research and/or illustrate their concerns with the construct's static nature (Davis \& Sumara 2006; Grumet 1990; Wolcott 1990). My thoughts about layers of intent and expression are aligned with this latter category.

Agar (2004) suggests that complexity science bears a striking resemblance to anthropology when applied to human beings. For example, he states that both can be characterized as iterative and recursive processes of emergent understandings. It is a constant tacking back and forth between data and frames of understanding. Over time, this movement generates new understandings that explicate local ideas, ideals, and practices in such a way that they can be interpreted by non-locals.

Complicity: An International Journal of Complexity and Education

Volume 5 (2008), Number $1 \bullet$ pp. 121-124 •www.complexityandeducation.ca 
Like validity, intentionality is also the site of much debate. Primarily, points of contention surround the degree to which any person: a) has her own intention (as opposed to a socially constructed understanding of what one can and cannot do); b) has the space to enact what they mean to do; or c) how much of what one observes is in fact what another has intended. Despite such concerns, Ortner (2006) maintains that although one's intention is highly situated and strongly contextualized (culturally, socially, economically, and so on), it is also integral to questions of agency-the spaces for individual actors to move within, around, through or subvert such contexts.

Noting the nested nature of both complexity science (Davis and Sumara 2006; Doll, Fleener, Trueit and St. Julien 2005) and cultural patterns such as sociocultural norms and values (Agar 1996; Erickson 1986; Varenne and McDermott 1998), one could argue that interpretive methodologists might use the relationship between one's intent and its expression in place of seeking a singular objective validity or a complex relocation of the construct. Intent is manifest in expression. The trouble lies in how much one can accurately (or truthfully or respectfully) gauge another's intent based on how that intent is expressed, through their interactions.

It is my contention that this particularly troubling point can be addressed through processes that are integral to strong ethnographic studies. Spending long periods of time in "the field," taking copious written notes, collecting documents, and often audioand/or video-taping local contexts provides multiple instances and iterations of actors' expressions. A glimpse into how actors frame the intent behind those expressions can be garnered through the interviews one collects (Spradley 1979). Because people's recollections of events change over time and can be changed in the context of an interview, and because their actions regularly do not match their stated intentions, interviews are not to be privileged over other data collected. Instead, they are placed alongside all other data in such a way that one situates the other (Agar 1986; Hammersley and Atkinson 1995).

Due to the socially constructed nature of human interaction, studenting (the broad set of possible student classroom interactions that includes learning, thinking, passing notes, looking out the window, sharpening pencils, and so on) and teaching share salient characteristics. They are both an expression of a given actor's intent and are contextualized by multiple layers of others' expressions of their intents. No one person's interaction in an educative context (be it in school or elsewhere), even committing words to a page, is not somehow informed by another's ideas, process of discourse, means of writing, and the like. Therefore, the expression of one person's intent is necessarily informed by the expression of others' intents.

As a result, the relationship between these layers of intent and expression can be seen as nested, folded into one another. In this way, an examination of how these layers of intent and expression are interrelated creates the space for researchers to consider what local interactions might mean and to whom such interactions matter, as well as the less-local interactions that situate and otherwise contextualize such interactions. A consideration of these nested layers also illuminates lines of power in any given interaction by demonstrating whose expressions tend to have greater influence on 
others' expressions and, conversely, whose expressions are more consistently are informed by others'. Additionally, an examination of layers of intent and expression can also allow the reader to see the intents behind the researcher's expressions of her writing, helping make her biases more transparent as she seeks to understand local actors' meanings.

It is precisely because this processes for identifying nested layers of intent and expression - interview, observation, collection of documents and the like - are central to interpretive studies of education that I suggest their purposeful alignment as a possible process to consider the meanings researchers construct. It is at any rate, I contend, a step in the direction away from wrestling with positivist-associated terms that are difficult to apply to interpretive studies of education.

\section{References}

Agar, M. H. (1986). Speaking of ethnography. Beverly Hills: Sage.

Agar, M. H. (1996). The professional stranger: An informal introduction to ethnography. (2nd ed.). San Diego, CA: Academic Press.

Agar, M. (2004). We have met the other and we're all nonlinear: Ethnography as a nonlinear dynamic system. Complexity 10(2), 16-24.

Davis, B. and Sumara, D. (2006). Complexity and education: Inquiries into learning, teaching and research. Mahwah, NJ: Lawrence Erlbaum.

Doll, W. E. Jr., Fleener, M. J., Trueit, D., and St. Julien, J. (Eds.). (2005). Chaos, complexity, curriculum \& culture: A conversation. New York: Peter Lang.

Erickson, F. (1986). Qualitative methods in research on teaching. In M. Wittrock (Ed.). Handbook of research on teaching (pp. 119-161). (3rd ed.). New York: Macmillan.

Geertz, C. (1973). The interpretation of cultures. New York: Basic Books.

Grumet, M. (1990). On the daffodils that come before the swallow dares. In E. Eisner and A. Peshkin (Eds.). Qualitative inquiry in education: The continuing debate (pp. 101-120). New York: Teachers College Press.

Hammersley, M. and Atkinson, P. (1995). Ethnography: Principles in practice. (2nd ed.). New York: Routledge.

Lather, P. (1986). Issues of validity in openly ideological research: Between a rock and a soft place. Interchange 17(4), 63-84.

Maxwell, J. (1990). Understanding and validity in qualitative research. Harvard Educational Review, 63(3), 279-300.

Ortner, S. B. (2006). Anthropology and social theory: Culture, power, and the acting subject. Durham, NC: Duke University.

Spradley, J. (1979). The ethnographic interview. New York: Holt, Rinehart, \& Winston.

Varenne, H., \& McDermott, R. (1998). Successful failure: The schools America builds. Boulder, CO: Westview Press.

Wolcott, H. F. (1990). On seeking-and rejecting-validity in qualitative research. In E. Eisner and A. Pushkin (Eds.). Qualitative inquiry in education: The continuing debate (pp. 121-152). New York: Teacher's College Press. 


\begin{abstract}
About the Author
Walter S. Gershon is an Assistant Professor in the Teaching, Leadership, and Curriculum Studies Department at Kent State University. His scholarly interests include questions about the relationship between curriculum and students, the ways that sociocultural precepts inform educational contexts such as classrooms, and the exploration of qualitative research methodologies. Prior to his time in higher education, Dr. Gershon taught students of all ages in urban settings in North America and overseas.
\end{abstract}

(c) Copyright 2008. The author, WALTER GERSHON, assigns to the University of Alberta and other educational and non-profit institutions a non-exclusive license to use this document for personal use and in courses of instruction provided that the article is used in full and this copyright statement is reproduced. The author also grants a non-exclusive license to the University of Alberta to publish this document in full on the World Wide Web, and for the document to be published on mirrors on the World Wide Web. Any other usage is prohibited without the express permission of the authors. 